\title{
El grito de la música, un golpe de emancipación
}

\author{
The scream of music, a blow of emancipation \\ O grito da música, um golpe de emancipação
}

\author{
Xavier Karolys ${ }^{1}$ \\ Universidad de Los Hemisferios (Ecuador) \\ ¡karolys88@gmail.com
}

Fecha de recepción: 25 de julio de 2019

Fecha de recepción evaluador: 23 de agosto de 2019

Fecha de recepción corrección: 20 de septiembre de 2019

\begin{abstract}
Despierta conciencias, motiva revoluciones, cambia mentalidades y destruye gobiernos. La música, en su forma más guerrillera, en su versión más subversiva, cuando se transforma en protesta y lucha, es un arma imparable porque alienta al cambio y a la revolución. (Lynskey)
\end{abstract}

\section{Resumen}

Esta exposición transcurre en los «márgenes», en el pensamiento y en la penumbra de un acontecimiento. Aquella dictadura militar (1976-1983) que envolvió a la sociedad argentina, arrebatando los derechos y la justicia de cada uno de los ciudadanos. Sin embargo, la vela de la música estuvo para combatir, y fue ahí donde el rock se manifestó en busca de liberación, de rebeldía y de expresión; exteriorizando el inicio de una emancipación. Este apartado reflexiona acerca de la influencia que tuvo Charly García al batallar la censura y la represión por medio del «arte». Una combinación de sonidos y

\footnotetext{
${ }^{1}$ Xavier Karolys Filósofo e Investigador. Licenciado en Ciencias Políticas y Relaciones Internacionales por la Universidad de los Hemisferios (Ecuador). Desarrolla una labor divulgativa, interesado en introducir la filosofía en los diferentes espacios de la sociedad. Ha sido invitado a dictar clases y participar en seminarios (p. ej., "Jean Paul Sartre: Un Siglo de Libertad") y conferencias (p. ej., "El Desvanecer del Presente"). En este contexto ha desarrollado investigaciones que giran en torno a la fenomenología y a la deconstrucción. ORCID: https://orcid.org/0000-0003-1985-9651.
} 
letras que impulsaron la inserción social de los derrotados, para despojarse de los dogmas, tomando la bandera de la acción.

Palabras claves: fenomenología, sociedad argentina, dictadura militar, rock, resistencia, emancipación.

\begin{abstract}
This exhibition takes place in the «margins», in the thought and in the gloom of an event. That military dictatorship (1976-1983) that enveloped the argentine society, snatching the rights and justice of each citizen. However, music was there to fight, and it was there where rock manifests itself in search of liberation, rebellion and expression; externalizing the beginning of an emancipation. This section reflects on the influence that Charly García had in fighting censorship and repression through «art». A combination of sounds and letters that drove the social insertion of the defeated, to shed the dogmas, taking the flag of action.
\end{abstract}

Keywords: phenomenology, argentine society, military dictatorship, rock, resistance, emancipation.

\title{
Resumo
}

Esta exposição ocorre nas «margens», no pensamento e na penumbra de um evento. Aquela ditadura militar (1976-1983) que envolveu a sociedade argentina, arrebatando os direitos e a justiça de cada cidadão. No entanto, a música estava lá para lutar, e foi lá que o rock se manifesta em busca de libertação, rebelião e expressão; externalizando o início de uma emancipação. Esta seção reflete sobre a influência que Charly García teve no combate à censura e repressão através da «arte». Uma combinação de sons e letras que impulsionaram a inserção social dos derrotados, para derramar os dogmas, levando a bandeira da ação.

Palavras-chave: fenomenologia, sociedade argentina, ditadura militar, rock, resistência, emancipação.

\section{Introducción}

El presente escrito busca insertarse en el estudio de la dictadura argentina, proponiendo un análisis fenomenológico que examine cómo la articulación del rock genero una transmisión del lenguaje que se concibió en resistencia. Se parte de la idea de Walter Benjamin en que "hay que cepillar la historia a contrapelo" o como diría Nietzsche "nadar contra las olas de la historia" 3 para entender ciertas implicancias que quedaron inadvertidas; y más si está el arte inmiscuido en ellas.

\footnotetext{
${ }^{2}$ Benjamin, Walter, La dialéctica en suspenso. Fragmentos sobre la historia. ARCISLOM, Chile, 1995.

${ }^{3}$ Nietzsche, Friedrich, Consideraciones intempestivas. Gráfico, Buenos Aires, 2016.
} 
No podemos olvidarnos cómo la estética de la existencia ha acompañado la animación rítmica de la vida. Los $a e d o s^{4}$, aquellos artistas de epopeyas que componían narraciones musicales conmoviendo el sentimiento del pueblo; o el gran poeta-músico Píndaro $^{5}$ quien influyó notablemente en la Grecia clásica. También los grandes trovadores y los juglares que interpretaban los acontecimientos cotidianos por medio de melodías alegres, desde una experiencia ambulante que se mezclaba en la sociedad. En sí, el arte de la música ha representado el impulso de expresar sentimientos, afectos y manifestaciones que posibilitan la transferencia de mensajes; generando una reconfiguración social.

En la década de los '70, se exhibe una fragmentación de la sociedad debido a los desequilibrios económicos, sociales y políticos que conducen a diez años de injusticias y violencia, generando la época más oscura de la Argentina. El monopolio de la dictadura militar engendró un Estado autoritario que provocó represión y violencia, con el objeto de establecer una ciudadanía alienada, para hacer uso y abuso de lo político.

Pero la subversión que tanto se jactaba el gobierno por desmantelar, comenzó a surgir con el rock nacional. Representando un movimiento de resistencia que manifestó su inconformidad, evocando factores significativos de libertad frente a la opresión. De tal forma, el desarrollo de este pensamiento busca abordar la influencia que tuvo Charly García en la sociedad argentina; y cómo la misma se identificó dentro de un marco social que articuló el descontento en el lenguaje musical. Es por esto que Habermas enfatiza que "la construcción de significados configura la cultura como punto de encuentro constitutivo de lo humano desde el lenguaje" (Habermas, 1989), ahora cabe preguntarse ¿fue posible neutralizar la dictadura con rock?

\section{Desarrollo}

Treinta mil desaparecidos, demasiados torturados, heridas de muerte, deuda externa multiplicada por seis, riquezas concentradas e injusticias; todo esto se reduce a un Estado déspota que dejo su tarea principal de lado, opacando el bienestar y la defensa de los ciudadanos. El 23 de septiembre de 1973 al extremo sur de América Latina, Juan Domingo Perón llega a la presidencia por tercera vez asumiendo la crisis internacional del petróleo. Pasan diferentes acontecimientos, uno de ellos lleva a emerger serios problemas en diversos destacamentos de la población y sin embargo aún había esperanza por un progreso. En el año 1974, la llama de la esperanza comienza a disminuirse por la pérdida de Perón que fue consumido lentamente por una broncopatía ${ }^{6}$.

Aquel año sale un álbum musical denominado "Pequeñas anécdotas sobre las instituciones", una banda que irrumpe con la melodía política a través de expresiones violentas y angustiantes que se comenzaron a vivir en climas agobiantes. Un inicio musical que buscaba la liberación de sentimientos por medio del rock and roll, aquel

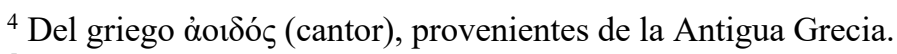

${ }^{5}$ Poeta lírico del siglo $\mathrm{V}$ a. $\mathrm{C}$.

${ }^{6}$ Afectación de los bronquios, alterando la tráquea y los pulmones.
} 
impulso de rebeldía, de discordancia y de expresión manifestaban el inicio de una emancipación.

De manera que, la política marxista se hace presente aludiendo que el sujeto lucha por protagonizar la demanda de una liberación, en donde se da la posibilidad de transformar el entorno; por este motivo Aristóteles como otros filósofos acentuaban que "la política es el arte de lo posible"; y desde este punto se arroja la semilla de la inserción social.

Aquel dúo rocker conformado por Nito Mestre y Charly García comienza a lanzar notas musicales, muy evidentes con la canción "instituciones" que alude a "los mangos, los acróbatas, los clowns mueven los hilos con habilidad" (Sui Géneris, 1974), exponiendo aquel mecanismo de orden social por parte de la organización política que arremetía la argentina. Pero todo orden social se teje en lo artificial.

De repente, toman a Charly García para el servicio militar, un malestar lo acompaña, puesto que se encontraba en una institución que el tanto combatía. Para evadir su estadía, el cantante ingiere todas las pastillas del botequín de emergencias e inmediatamente sube al balcón, esperando un suceso venir. Pero el suceso no fue el final de lo finito, sino que compone una de las mejores canciones denominada "canción para mi muerte", ¿su composición era porque esperaba su muerte venir o por la sujeción asesina que había comenzado el Estado?

La ocurrencia no lo hace escapar del aparato militar, por lo cual toma una decisión inusual y "agarra a un soldado muerto, le pone en una silla de ruedas y le saca a pasear. Cuando le descubren, expresa que ese hombre estaba muy pálido" (Charly García Biografías, 2013), esta acción lo expone ante la sociedad con la etiqueta de maníaco depresivo con temperamento esquizoide ${ }^{7}$ y a través de ello se libra del servicio militar. ¿Pero a costa de qué? ¿de un acto de posicionamiento que sostiene una construcción social que marca relaciones de determinación?, ello levaría como mínimo a centrase en conceptos de categorización que responden a un interés.

E1 24 de marzo de 1976, se abre la etapa de un nuevo golpe cívico denominado "Proceso de Reorganización Nacional" que arremete el poder "amenazando a los más variados ámbitos de la vida social, constituyendo el principal recurso de cohesión de identidad militar en un contexto de significativas diferencias ideológicas" (Vera, 2001). Este hecho genera que las fuerzas armadas realicen una actuación conjunta, es decir se van a distribuir el domino o la potestad por igual; desde ya se denota una disputa entre semejantes.

El golpe se va anunciando dentro del mandato de Isabel Perón, que desde los inicios se ve envuelto por la ola de crisis. El plan estratégico aprovecha el momento, para que varios sectores, como: la sociedad rural, la prensa, los grupos financieros y los sectores más conservadores de la iglesia católica se unan y propaguen una nueva

\footnotetext{
${ }^{7}$ Se caracteriza por introversión y aislamiento social, girando en una fantasía.
} 
dictadura. Lo que se buscaba "era volver atrás las reformas económicas y sociales hechas por el peronismo e instaurar un nuevo orden social" (Pigna, 2015), regresamos de nuevo, ¿pero qué buscaba ese orden artificial? ¿Qué hay atrás de esa trama? ¿Exclusión? ¿O acaso querían una clase obrera dócil?

El poder de este gobierno es asumido por la junta de comandantes, sin embargo, comienza a disputarse el liderazgo entre Emilio Massera que era el comandante de la Armada (antiperonista) y Jorge R. Videla comandante del ejército que buscaba una salida democrática ante la situación.

E1 29 de marzo del mismo año, las guerrillas quedan derrotadas y es designado al mandato provisional Videla que inmediatamente exclama: "Queremos garantizar la paz en toda la república, para ello acabaremos con la subversión" (Diario Clarín , 1976). Esa experiencia lingüística que pretendía generar el slogan de la "lucha subversiva", se esparce a todas las personas que no estén acorde con la dictadura para así poder disciplinar a sangre fría.

En este mismo año, Charly García crea con otros integrantes la banda de rock progresivo "La Máquina de Hacer Pájaros" que saca el álbum películas manifestando una guerra contra la represión que regía el país. En una de sus canciones remarca sentimientos de desconfianza y de paranoia ante el accionar del gobierno, por medio de metáforas como lo haría Nietzsche.

Cuando la noche te hace desconfiar, yendo por el lado del río, la paranoia es quizás nuestro peor enemigo. Cubrís tu cara y tu pelo también como si tuvieras frío, pero en realidad te querés escapar de algún lío (...) déjenme en paz, no quiero más, no hay esperanza en la ciudad. (La Máquina de Hacer Pájaros, 1977)

El acontecimiento se sigue agravando, de tal forma que se produce un alto nivel de censura; ordenando la retención y la quema de libros. Es ahí, donde el poder aplica una política vertical- descendente que restringe las libertades. Fernando Ferreira entiende que "la inseguridad frente a la propia limitación intentan destruir al otro" (2000), situándose en una dimensión de abatimiento porque la mismidad detona donde el otro irrumpe. Para la filosofía levinasiana el «otro» nos compromete por medio de su rostro ${ }^{8}$; para no dejarnos indiferentes. En este caso haciendo alusión al rostro argentino.

Incluso, "se montan centros clandestinos de detención con salas de tortura. Contando con 350 centros, los más activos eran: La Escuela de Mecánica de la Armada, El Vesubio, La Perla, Córdoba y en la Provincia de Tucumán" (Pigna, 2015). Antes de realizar la retención a las personas "sospechosas" para llevarles a los centros de tortura se pedía la orden de zona liberada ${ }^{9}$, con la intención de realizar sus acciones sin inconvenientes.

\footnotetext{
${ }^{8}$ Expresión que demanda respuesta.

${ }^{9}$ La suspensión de la ley, otorgando el permiso de los operativos.
} 
En ese momento comienza a desplegarse el régimen de excepción bajo el estricto estado de sitio $^{10}$, lo que hará que las reuniones públicas estén prohibidas. Se procederá a la intervención en cualquier lugar y sobre todo a la detención o confinamiento sin mandato judicial.

Los sucesos que se vivían en esta temporalidad comprometieron al rock como la esperanza de manifestación social, la música represento la voz de la euforia en un mundo sombrío. El grupo de rock poseía la voz de los oprimidos, así que expreso la canción "No te dejes desanimar", para alentar la lucha por la libertad y despojarse del yugo de la opresión.

Estás harto de ver los diarios, estás harto de los horarios, estás harto de estar en tu lugar, ya no escuchas el canto de los mares, ya no sueñas con lindos lugares, para descansar una eternidad, no te dejes desanimar (...) quedan tantas mañanas por andar (La Máquina de Hacer Pájaros, 1977).

Es ahí, donde la vanguardia social se desarrolla por medio de significados y sentidos que hacen que la palabra pública ya no pase desapercibida. Las calles se vuelven lugares de re-significación que inquieta el deseo por reivindicar la democratización a través de batallas simbólicas.

Tanto en los sesenta, setenta y parte de los ochenta, la euforia embriagante del rock comienza a desplegarse. Aquellas bandas como The Who, Beatles, The Police, Stones, Jimmy Hendrix, The Doors, Charly, entre otras; generan una multitextualidad urbana. A eso Bauman lo llamaría "comunidades estéticas" que desmarca los límites de lo privado y lo público por medio de signos de identidad. En ese punto se hace necesario reflexionar en torno a los componentes identitarios, aunque estos siempre estén en constante proceso o como expresaría la literatura francesa un "flâneur" que se transforma todo el tiempo.

El individuo oye música de la mañana a la noche, como si tuviera necesidad de permanecer fuera, de ser transportado y envuelto en un ambiente sincopado, como si necesitara una desrealización estimulante, eufórica o embriagante del mundo (Lipovetsky, 1986), envuelto por el ritmo y por una relación dialéctica.

Por su parte, la construcción de identidad social se inserta paralelamente con la articulación de relatos; en donde un (yo) se reconoce participe de una comunidad significativa. Estamos entramados en un constructo mental que activa los estímulos para crear un espacio de encuentro, mediante la profundidad emocional y la intimidad personal; dando como resultado comunidades transitorias. Estas intensidades multifrenéticas reivindican la experiencia para avenirse como sujetos del sentido social.

En el caso particular de la Argentina, la música fue integrando formaciones contingentes que buscaban la liberación de la opresión, eso hizo propia la pertenencia al

\footnotetext{
${ }^{10}$ Restricción de varios derechos constitucionales.

${ }^{11}$ Caminar sin rumbo, abierto a los múltiples caminos del presente.
} 
grupo que dirigió su mirada hacia la movilidad social. Si la creencia está en el cambio, el interaccionismo debe ser amplio; y para ello posibilitar la unidad.

Mientras tanto, en la parte económica hay un paralelismo que no se queda atrás. El "Grupo Perriaux" consistía en un sector de empresarios que deseaban la apertura económica.

El gobierno designa a un nuevo ministro de economía que sería José Martínez de Hoz que plantea dos males que no permiten el progreso del país: la clase obrera es demasiado demandante e indisciplinada y una industria nacional ineficiente (Pigna, 2015).

¿Demandante e indisciplinada? ¿a qué se refiere? ¿no habla Martínez de la Hoz de un factor de proletarización? Parece que la ultra derecha lo único que quiere es definir el marco del proletario para que siga subordinado a las condiciones de explotación, y de ello se beneficie la burguesía. He aquí, la famosa llamada "salida política" implementada por el ministro de economía que consistía principalmente en eliminar el control de precios y congelar los salarios; causando una afectación directa al bolsillo de los ciudadanos.

Regresando al otro lado de la moneda, los dirigentes militares Luciano Menéndez y Guillermo Suárez Mason llevaron a cabo estrategias siniestras; una de ellas fue la disposición de "que sean eliminados todos" (Vera, 2001). Este hecho desembocó el perverso método del traslado que consistió en lanzar los cuerpos al Río de la Plata.

Emilio Massera lanzó un comunicado, expresado: "Esto es una guerra entre la libertad y la tiranía, lo cierto, lo absolutamente cierto es que aqui y en todo el mundo; luchan los que están a favor de la muerte y los que estamos a favor de la vida" (Diario Clarín , 1976), esto claramente no era de ese modo, pero la propaganda debería manifestarse de esa manera; desde los márgenes de la impostura y el descaro.

La morfología social del arte sigue dando batalla, sigue generando voz entre tanto mal, esparciendo una identidad que proclama la expresión de lo humano; manifestando la intranquilidad. "La música va ligada a cualquier revolución por una simple razón: es una muestra de cultura, un fragmento en movimiento" (Fuentes, 2010), aquel movimiento posibilita un cambio dentro de las estructuras del entorno dictatorial.

"Sobre la T.V. se duermen mis gatos, salgo a caminar para matar el rato y de pronto yo la veo entre los autos, cuando la luz roja cierra el paso me acercaré al convertible, le diré: quiero ser libre (...)" (La Máquina de Hacer Pájaros, 1977). Se puede observar las metáforas impactantes que demuestran la represión vivida, donde se aprecia que el "rojo" es la restricción y el "convertible" el Estado; aquella entidad que despilfarra el dinero del pueblo en su propio beneficio. Es por eso que se da lugar a un reapropiamiento de lo expropiado que en este caso sería la libertad.

En consecuencia, en abril de 1977 la subversión se comienza a ver, grupos civiles rompen la impunidad y el silencio. Uno de estos grupos proclama su desasosiego puesto que sus hijos fueron apropiados por los militares, "las distintas madres al estar prohibidas las reuniones, comienzan a moverse en círculo alrededor de la plaza de mayo, este 
acontecimiento lleva a inquietar a los militares, porque llaman la atención de periodistas extranjeros" (Pigna, 2015).

El periódico británico "Buenos Aires Herald”, saca una columna en inglés; lo cual le proporciona cierta impunidad para escribir libremente. El movimiento de las madres comienza a ser escuchado.

Videla por medio de una rueda de prensa, expresa:

Frente al desaparecido en tanto éste como tal, es una incógnita el desaparecido. Si el hombre apareciera tendría un tratamiento X, si la aparición se convirtiera en certeza de su fallecimiento tiene un tratamiento $Z$, pero mientras sea desaparecido no puede tener un tratamiento especial es un desaparecido, no tiene entidad, no está muerto ni vivo, está desaparecido; frente a eso no podemos hacer nada (1979).

Cómo se puede decir que "frente a eso no podemos hacer nada"; responde a una falacia tanto de su (ser) como la del (conocer). ¿No será más bien que el fantasma es la dictadura? O para decir en términos marxistas "Un fantasma recorre la Argentina, el fantasma de la dictadura", aquel fantasma aterra, ya que despliega un propósito de control que se transforma en un panóptico ${ }^{12}$.

El gobernante de la armada Massera realiza tareas de inteligencia, adhiriendo una infiltración de un joven denominado "Gustavo Niño" en las rondas de las madres. Este joven se presentaba como aquel muchacho que su hermano había desaparecido, tratando de adecuarse en el movimiento.

En el lapso de 1977 el grupo comienza a juntar dinero para pagar una publicación en el diario "La Nación" que conste con todos los nombres de los desaparecidos. Los integrantes se reúnen en sigilo dos días antes en el barrio de San Cristóbal para planear su siguiente movimiento. Gustavo Niño al marcharse del sitio, se despide con sutileza de ciertos integrantes del grupo; poco después, los policías detienen a nueve personas, aquellas personas estaban marcadas con un beso, un beso de traición, el beso de judas. (Pigna, 2015)

Para estas fechas ya no había "Sui Generis”, ni "La Máquina de Hacer Pájaros"; ahora se consagraría el proceder de "Serú Girán" que tardó también para llegar al oyente. El rock nacional comenzó de nuevo a ejercer los acontecimientos por medio de letras directas que envolvían la percepción de la realidad.

De este modo, "las asociaciones paradigmáticas surgen porque el estímulo es una palabra que aparece en el lugar donde el oyente tiene preparadas esta y otras palabras afines" (Hormann, 1973), eso es lo que proporciona una relación cercana entre el hablante y el oyente. En este caso se empareja el estímulo doloroso de la dictadura.

"Estamos ciegos de ver, cansado de tanto andar. Estamos hartos de huir en la ciudad. Nunca tendremos raiz, nunca tendremos hogar y, sin embargo, ya ves... somos

\footnotetext{
${ }^{12}$ Arquitectura carcelaria de vigilancia.
} 
de acá" (Serú Girán , 1978), los aplausos se escuchaban como gotas que caen en el cemento, debido a que fue un referente que no se quedó callado y hablo por cada uno de los argentinos, a pesar de estar expuesto ante la represión.

Al llegar 1978, se destaca un hecho que soslaya la burbuja financiera que se veía venir. La gente comenzó a centrarse por el fútbol, dejando a un lado las problemáticas económicas que estaban atravesando. Un plan perfecto para el gobierno, "el Mundial del 78 ", olvida las grietas y construye una imagen de orden.

¿No es acaso el fútbol un dispositivo de enajenación? ¿Aquel opio que entumece la revolución para dominar las masas populares y desviar la crisis del momento? Si se realiza un análisis divergente del "entretenimiento ingenuo", nos vamos a encontrar con una narrativa proto-violatoria que sublima la violencia por medio del juego.

Un trampolín político que se normaliza por medio de una simbología de reconocimiento o afinidad, a través de una representación socio-cultural que expresa sentimientos comunitarios. Pero atrás de los sentimientos comunitarios hay un mecanismo de poder que controla adecuadamente las emociones, o desde la perspectiva metafórica de Benjamin, "el enano movía los cordeles del autónoma"l13.

La euforia del triunfo argentino pone de celebración las calles; esto hace que la dictadura mezcle la felicidad del fútbol como que fuera apoyo al gobierno. Es por eso que el general Roberto Viola en uno de sus discursos hace hincapié al momento:

argentinos: hemos sido capaces de vencer a la insidia y el escepticismo. Seamos ahora también capaces, con la ayuda de Dios, de impulsar a la nación en pos de sus objetivos. Tanta alegría, tanto entusiasmo generosamente expresados no son un fruto casual, responden en definitiva al profundo anhelo de la unión nacional que sentimos todos los argentinos (Suárez, 2000).

Para 1979, por medio de la presión, Videla recibe a la $\mathrm{CIDH}^{14}$. Llegan los observadores para proporcionar información sobre los sucesos que estaban aconteciendo la Argentina, notificando la siguiente resolución informativa. "Está incurriendo el gobierno en un acto de misión y estarían violando los derechos de esas personas a no ejercer las facultades que tienen según la constitución y las leyes de la república" (Andrés Aguilar, Presidente de la CIDH). De manera que la junta militar, sin descaro reparte miles de calcomanías con el tema "los argentinos somos derechos y humanos" (Diario Clarín , 1976).

En 1981 la crisis estalla, Roberto Viola con nuevos planes en mente intenta hacer que la sociedad argentina empuje para un cambio a lo largo de estos cinco años de letargo. Sin embargo, muchos partidos no están de acuerdo y llaman a elecciones. Este hecho hace que el ejército le bote del poder a Viola y coloque en el mandato a Leopoldo Galtieri, que se centra en levantar la imagen de la fuerza armada. (Pigna, 2015)

\footnotetext{
${ }^{13}$ Benjamin, Walter, Tesis de la Filosofia de la Historia.

${ }^{14}$ Comisión Interamericana de Derechos Humanos.
} 
El 30 de marzo de 1982, surge una de las más grandes movilizaciones que se centran en la Plaza de Mayo, adheridos el lema "paz, pan y trabajo", diferentes sectores se reivindicaron por medio de herramientas populares; expresando el malestar. Inmediatamente Galtieri reprimió sin tregua a cada uno de los grupos y utilizó la propaganda para enfocar a la sociedad en "La guerra de las Malvinas".

Este acontecimiento tiene una imagen particular en el género popular, tanto así que se organizan colectas solidarias, pero lastimosamente nunca llegan al destino. Un problema total, se vuelve a usar a la sociedad manipulando su sentimiento y más aún, cuando el Estado divulga "la victoria argentina", un hecho muy distinto a lo que pasaba en la realidad.

Ante eso, Charly García quiso representar su propio sentimiento en un festival que lo denominó "No bombardeen Buenos Aires" en el estadio de Ferro donde hizo estallar la escenografía, representando el panorama que vivían los soldados en Malvinas. Además, enfatizo en su canción "Superhéroes", "No pasa nada, nadie pasa, sólo una banda militar desafinado el tiempo y el compás" (Charly García , 1982).

El 14 de junio, el comando argentino se rinde; evaporando inmediatamente el fervor popular. Los militares lanzan su último "As" en la mesa, dictando la ley " $N$. 22.924" que establece como artículo 1 "extinguir las acciones penales emergentes de los delitos cometidos con motivación o finalidad terrorista o subversiva" (Martin Prieto, 1983), generando una norma a su conveniencia.

Mientras la sociedad atravesaba estas injusticias ante sus ojos, Charly seguía siendo un gestor cultural que plasmó otro de sus grandes éxitos denominado "Nos siguen pegando abajo" que contaba el hecho de la insolencia militar.

Yo estaba en un club, no había casi luz. La puerta de salida tenía un farolito azul, él se desmayó delante de mí; no fueron las pastillas fueron los hombres de gris. Miren lo están golpeando todo el tiempo, lo vuelven a golpear...nos siguen pegando abajo (Charly García ).

¿Hay cómo salir de la alienación o enajenación? ¿Despojarse de la injusticia? ¿Del sometimiento? Uno de los filósofos de la sospecha respondería que sí, por medio de la revolución. Aquella es la forma de lucha que conduce al poder del pueblo hacia el bien general, replanteando las ideas foucaultianas "donde hay poder, hay resistencia" 15 ; optemos por la revolución.

En 1983 vuelven a votar, el país ya comienza a poseer un ámbito democrático a pesar de los siete años de dictadura que abusaron y restringieron a cada uno de los ciudadanos, vulnerando sus derechos y su vida.

\footnotetext{
${ }^{15}$ Foucault, M, Historia de la sexualidad: Vol. 1: La voluntad de saber.
} 
"Será porque nos queremos sentir bien, que ahora estamos bailando entre la gente. Será porque nos queremos sentir bien, que ahora todo suena diferente" (Charly García ).

\section{Consideraciones Finales}

A lo largo de estas palabras, se ha realizado una recapitulación de la época más sombría de la Argentina. Aquella temporalidad que infringió severamente a la sociedad por medio de la represión, la censura y la violación de los derechos humanos. El enemigo de la patria era el propio Estado, aquellos quienes alimentaban la violencia para quedarse con el poder.

En la fábula "El lobo y el cordero", Derrida analiza que "la razón es siempre la del poder" 16 , un dominio que subordina a las minorías; que al mismo tiempo es "lo otro", el otro que vive la injusticia desde su disolución.

A pesar de ello, surge una expresión cultural que se contrapone al sistema represivo, el rock refuerza el protagonismo de los derrotados por medio de la música. Esta composición reconfigura el esquema, desplazando las fronteras para engendrar lazos de identidad que impacten en el seno social por medio de la resistencia.

En el rock da batalla Charly García se convierte en un catalizador cultural que crea mosaicos musicales, elaborados con demandas e inconformidades que parten de la voz popular. La sinfonía ha posibilitado la trasmisión de mensajes, expresando libremente el sentimiento en las circunstancias más adversas. Cada letra evoca resistencia, cada canción una significación, cada experiencia una herramienta y todo ello para promover la acción.

“'Sí! iSé de dónde procedo! Insaciable cual la llama quemo, abrazo y me consumo. Luz se vuelve cuanto toco y carbón cuanto abandono: llama soy sin duda alguna" (Nietzsche, 1979), aquella llama que se consume por llegar a re-apropiar su libertad.

\section{Bibliografía}

Charly García (1982). Superhéroes .

Charly García - Biografías. (2013). Youtube. Obtenido de Youtube: https://www.youtube.com/watch?v=zHbJVXAUHYc

Diario Clarín . (30 de Marzo de 1976).

Ferreira, F. (2000). Una historia de la censura. Violencia y proscripción en la Argentina del siglo XX. Buenos Aires : Norma .

Fuentes, C. (2010). El espejo enterrado. México : Fondo de Cultura Económica .

\footnotetext{
${ }^{16}$ Derrida, J, La bestia y el soberano I.
} 
Habermas, J. (1989). Teoría de la acción comunicativa . Madrid: Taurus .

Hormann, H. (1973). Psicología del lenguaje . Madrid: Gredos, S.A.

La Máquina de Hacer Pájaros (1977). Películas. Argentina.

Lipovetsky, G. (1986). La era del vacío. Ensayos del individualismo contemporáneo. Barcelona: Anagrama.

Martin Prieto . (24 de Septiembre de 1983). El País . Obtenido de elpais.com/diario/1983/09/24/internacional/433202403_850215.html

Nietzsche, F. (1979). Ecce Homo. Madrid: Peralta, Ediciones .

Pigna, F. (25 de Septiembre de 2015). Canal Encuentro . Obtenido de youtube.com $/$ watch? $\mathrm{v}=$ Dhvn6jk $1 \mathrm{nM}$

Serú Girán (1978). La Grasa de las Capitales.

Suárez, O. (2000). Los cuerpos del poder . Roca Editorial.

Sui Géneris (1974). Instituciones. Argentina.

Vera, P. (2001). La legitimación del Proceso de Reorganización Nacional y la construcción de la amenaza en el discurso militar. La Plata : Universidad Nacional de La Plata.

Videla, J. (1979). Conferencia de Prensa . 